\title{
OPTICAL ROTATORY RELATIONSHIPS EXHIBITED BY AROMATIC AND ALIPHATIC GLYCOSIDES
}

\author{
By William Ward Pigman and Horace S. Isbell
}

\begin{abstract}
A comparison of the rotations of a large number of glycosides reveals that aromatic groups in general (phenyl and substituted phenyls) produce rotational effects quite different from those produced by ordinary aliphatic radicals. These influences are manifested in several ways: (1) When an aromatic nucleus is attached to an asymmetric carbon through an oxygen linkage, the rotatory contributions of other asymmetric carbons attached to this carbon are greater by a fairly constant amount than they are when the attached group is an aliphatic radical. Using Hudson's concept, this may be expressed by the statement that the $2 B$ values for aromatic glycosides are usually 9,000 to 13,000 greater than the $2 B$ values for the aliphatic glucosides. (2) Aromatic $\beta$-glucosides (substitutedphenyl $\beta$-glucosides) usually are considerably more levorotatory than the aliphatic $\beta$-glucosides. Phenyl $\beta$-glucosides when substituted with "ortho-para directing groups" in any position or ordinarily with "meta directing groups" in the ortho position have molecular rotations in the region of $-17,000$ to $-20,000$, whereas the molecular rotations of the aliphatic $\beta$-glucosides, with the exception of the glucosides of the tertiary alcohols, all fall between $-6,500$ and $-9,500$. However, "meta directing groups" in the meta and para positions increase the molecular rotations to values greater than $-20,500$, and for $p$-nitrophenyl $\beta$-glucoside the molecular rotation is $-31,130$. An interesting "diortho effect", which consists in a marked decrease in the optical rotation caused by the substitution of two groups in the ortho positions of phenyl $\beta$-glucoside, is pointed out. It is shown that in a series of related glucosides, aliphatic or aromatic, the molecular rotations of the $\beta$-glucosides are directly proportional to the rotatory contributions of the
\end{abstract} glucosidic carbons.

A correlation is demonstrated between the molecular rotations of certain substituted-phenyl $\beta$-glucosides and the $p K$ values of the corresponding phenols. This relationship is similar to that previously found by Betti for a different series of active compounds. The parallelism between the dissociation constants of the phenols and the optical properties of the corresponding glucosides supports the hypothesis that the optical rotation is conditioned by the same intramolecular electronic forces as those which control the dissociation of the phenolic hydrogen. The effect is presumably exerted through the electrons forming the bond between the phenolic oxygen and the glucosyl group.

Experimental details for the preparation of the phenyl $a$ - and $\beta$ - $d$ - $\alpha$-glucoheptosides (and pentaacetates), the phenyl $\alpha$ - and $\beta-\alpha-\alpha$-mannoheptosides, and phenyl $\alpha$ - $d$-taloside (and tetraacetate) are described. The optical rotations and melting points of these new substances are given.

\section{CONTENTS}

I. Introduction

II. Comparison of optical rotations of glycosides.

1. Relation between the values of $2 A$ of glucoside pairs and the molecular rotations of the corresponding $\beta$ - $d$-glucosides 
III. Relations between the structure of the aglucon group and the optical rotation

IV. Correlation of the optical rotation of aromatic glycosides with the dissociation constants of the corresponding phenols...........

V. Experimental details

1. General procedure $\ldots \ldots \ldots$

2. Phenyl $d$-a-mannoheptosides . . . . . . . . . . . . . . . . .

3. Phenyl $d$-talosides $\ldots \ldots$

4. Phenyl $d$-a-glucoheptosides

VI. References

\section{INTRODUCTION}

The numerous data available for the optical rotations of the alpha and beta modifications of the phenyl and substituted-phenyl glycosides make possible many interesting correlations between the optical rotations and other properties of the aromatic glycosides. For correlating optical rotation and structure Hudson $[1,2]{ }^{1}$ has expressed several rules. The so-called first rule of isorotation relates to the optical rotation of the glycosidic carbon. If the formulas for $\alpha$ - and $\beta-d$ glucose are written as ring structures differing solely in the configuration of carbon 1 , and if the rotation which is due to carbon 1 is called $A$, and the rotation which is due to the rest of the molecule is called $B$, the molecular rotation of one isomer can be represented as $+A+B$ and the rotation of the other isomer as $-A+B$. The sum of the rotations is then $+2 B$ and their difference $+2 A$. When the molecular rotations of the alpha and beta modifications of substances having like glycosidic groups, like ring structures, and like configurations on the adjacent carbon atoms are compared, it has been observed that the differences ( $2 A$ values) are nearly constant. This approximate equality is the basis of the first rule of isorotation, which states $[2$, p. 61] "the rotation of the carbon 1 in the case of many substances of the sugar group is affected in only a minor degree by changes in the structure of the remainder of the molecule." The sum of the molecular rotations of the alpha and beta sugars, $+2 B$, varies from sugar to sugar; but if the sums of the molecular rotations of the sugars are compared with the sums of the molecular rotations of the methyl glycosides, it will be observed that the values of $2 B$ obtained for the sugars are close to the values of $2 B^{\prime}$ obtained for the corresponding methyl glycosides. This is the basis for Hudson's second rule of isorotation which states [2, p. 63] "changes in the structure of carbon 1 in the case of many substances of the sugar group affect in only a minor degree the rotation of the remainder of the molecule."

Hudson has investigated the effect of variations in the glycosidic aglucon group on the values of $B$ and has shown that changes in the structure of the aglucon group produce only small effects on the rotatory contributions of the remaining carbon atoms $(2 B)$. But as pointed out by several authors [3,4], the value of $2 B$ obtained for the phenyl $\alpha$ - and $\beta$ - $\alpha$-glucosides differs considerably from the value obtained for the methyl $\alpha$ - and $\beta$ - $\alpha$-glucosides and related substances. According to one of the current theories for the origin of optical rotation [5], the introduction of a chromophoric group at one point in an optically active substance induces a change in the optical rotation of

1 Figures in brackets indicate the literature references at the end of this paper. 
the rest of the molecule. The chromophoric group is particularly influential when adjacent to an asymmetric center, as for example, in the benzyl glucosides.

The preparation of numerous substituted-phenyl $\alpha$ - and $\beta$-glycosides, particularly by Helferich and coworkers [6] as well as others, makes possible the comparison of the optical rotations of a wide variety of aromatic glycosides. Such comparisons furnish information concerning the effect of substitution in the benzene ring on the optical rotation of the corresponding glycosides, and perhaps on the origin of optical rotation.

\section{COMPARISON OF OPTICAL ROTATIONS OF GLYCOSIDES}

\section{1. $2 B$ VALUES FOR AROMATIC AND ALIPHATIC GLYCOSIDES}

In table 1 are recorded the values for $2 A$ and $2 B$ for the aromatic and aliphatic glucosides, galactosides, mannosides, arabinosides, and rhamnosides and their acetylated derivatives for which the optical rotations of both the alpha and beta isomers have been found in the literature. The phenyl $d$ - $\alpha$-glucoheptosides and $d$ - $\alpha$-mannoheptosides are new compounds reported in this paper.

The $2 B$ values for the aliphatic and aromatic glycosides of the same sugar differ by significant amounts. The alkyl glucosides have an average value for $2 B$ of 23,200 , while the phenyl, nitrophenyl, and $p$-hydroxyphenyl glucosides average 32,160 , or almost 40 percent more. Inspection of table 1 reveals that the $2 B$ values for the aromatic and aliphatic glycosides of arabinose, galactose, $d$ - $\alpha$-glucoheptose, $d$ - $\alpha$-mannoheptose, $d$-mannose, and $l$-rhamnose also differ by substantial amounts. It is interesting to note that the benzyl glucosides have a value for $2 B$ slightly lower than the normal value for the aliphatic series. The introduction of a methylene $\left(\mathrm{CH}_{2}\right)$ group between the aromatic nucleus and the asymmetric carbon reduces the effect of the phenyl group, so that the benzyl glucosides have a value near that for the aliphatic series.

It may also be seen from table 1 that the same qualitative differences are observable for the acetylated glycosides. The most striking effect is shown by the acetylated $d$ - $\alpha$-glucoheptosides, for which the difference between the $2 B$ values for the phenyl and methyl glycosides is about 47,000 , or more than 100 percent greater than the $2 B$ value for the methyl $d$ - $\alpha$-glucoheptosides. 
TABLE 1.-Sums and differences of molecular rotations of alpha and beta pairs of sugars, glycosides, and acetylated derivatives a

\begin{tabular}{|c|c|c|c|c|}
\hline \multirow{3}{*}{ Substances } & \multirow{2}{*}{\multicolumn{2}{|c|}{ 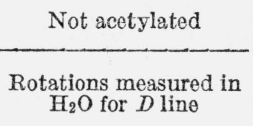 }} & \multicolumn{2}{|c|}{ Acetylated } \\
\hline & & & \multicolumn{2}{|c|}{$\begin{array}{l}\text { Rotations measured in } \\
\mathrm{CHCl}_{3} \text { for } D \text { line }\end{array}$} \\
\hline & $\begin{array}{l}\text { Differ- } \\
\text { ence, }{ }^{b} 2 A\end{array}$ & Sum,, $2 B$ & $\begin{array}{c}\text { Differ- } \\
\text { ence, } 82 A\end{array}$ & Sum, ${ }^{\circ} 2 B$ \\
\hline $\begin{array}{l}l \text {-Arabinose } \\
\text { Methyl } l \text {-arabinosides } \\
\text { Ethyl } l \text {-arabinosides. } \\
\text { Phenyl } l \text {-arabinosides. }\end{array}$ & $\begin{array}{l}17,050 \\
37,460 \\
39,040 \\
53,610\end{array}$ & $\begin{array}{l}40,170 \\
43,140 \\
44,180 \\
56,330\end{array}$ & 33,300 & 60,300 \\
\hline $\begin{array}{l}d \text {-Galactoses } \\
\text { Methyl } d \text {-galactosides } \\
\text { Phenyl } d \text {-galactosides } \\
\text { o-Tolyl } d \text {-galactosides }\end{array}$ & $\begin{array}{l}17,640 \\
38,220 \\
65,810 \\
62,510\end{array}$ & $\begin{array}{l}36,660 \\
37,940 \\
45,410 \\
39,100\end{array}$ & $\begin{array}{l}32,790 \\
53,270 \\
74,780 \\
77,590\end{array}$ & $\begin{array}{l}50,750 \\
43,130 \\
74,180 \\
74,090\end{array}$ \\
\hline $\begin{array}{l}d-\alpha \text {-Glucoheptoses } \\
\text { Methyl } d \text { - } \alpha \text {-glucoheptosides } \\
\text { Phenyl } d \text { - } \alpha \text {-glucoheptosides }\end{array}$ & $\begin{array}{l}41,790 \\
72,340\end{array}$ & $\begin{array}{r}8,210 \\
20,980\end{array}$ & $\begin{array}{l}38,010 \\
53,600 \\
78,930\end{array}$ & $\begin{array}{l}42,450 \\
39,700 \\
86,870\end{array}$ \\
\hline $\begin{array}{l}d \text {-Glucoses } \\
\text { Methyl } d \text {-glucosides } \\
\text { Ethyl } d \text {-glucosides } \\
\text { Propyl } d \text {-glucosides }\end{array}$ & $\begin{array}{l}16,840 \\
37,500 \\
39,290 \\
39,890\end{array}$ & $\begin{array}{l}23,580 \\
24,220 \\
24,010 \\
22,690\end{array}$ & $\begin{array}{l}38,220 \\
54,870 \\
58,250\end{array}$ & $\begin{array}{l}41,180 \\
40,690 \\
41,170\end{array}$ \\
\hline $\begin{array}{l}n \text {-Hexyl } d \text {-glucosides- } \\
\text { Ethylene glycol } d \text {-glucosides. } \\
\text { Allyl } d \text {-glucosides } \\
\text { 1,3-Propane glycol } d \text {-glucosides } \\
\text { Cyclohexyl } d \text {-glucosides. } \\
\text { Benzyl } d \text {-glucosides }\end{array}$ & $\begin{array}{l}37,240 \\
38,290 \\
41,380 \\
45,800 \\
49,870\end{array}$ & $\begin{array}{l}23,520 \\
19,710 \\
24,140 \\
24,080 \\
20,950\end{array}$ & $\begin{array}{r}59,030 \\
62,620 \\
85,750\end{array}$ & $\begin{array}{l}41,810 \\
42,140 \\
39,890\end{array}$ \\
\hline $\begin{array}{l}\text { Phenyl } d \text {-glucosides } \\
p \text {-Nitrophenyl } d \text {-glucosides } \\
p \text {-Aminophenyl } d \text {-glucosides } \\
p \text {-Hydroxyphenyl } d \text {-glucosides } \\
p \text {-Benzoylphenyl } d \text {-glucosides. }\end{array}$ & $\begin{array}{r}67,780 \\
95,800 \\
\text { d } 70,280 \\
65,910\end{array}$ & $\begin{array}{r}31,400 \\
33,740 \\
\mathbf{a} 3,020 \\
31,330\end{array}$ & \begin{tabular}{l}
80,640 \\
\hdashline 82,860
\end{tabular} & 61,960 \\
\hline $\begin{array}{l}d-\alpha \text {-Mannoheptoses } \\
\text { Phenyl } d-\alpha \text {-mannoheptosides }\end{array}$ & $\begin{array}{l}17,730 \\
70,650\end{array}$ & $\begin{array}{l}37,030 \\
47,870\end{array}$ & . & ........... \\
\hline $\begin{array}{l}d \text {-Mannoses } \\
\text { Methyl } d \text {-mannosides } \\
\text { Phenyl } d \text {-mannosides. }\end{array}$ & $\begin{array}{r}8,340 \\
28,930 \\
47,430\end{array}$ & $\begin{array}{r}2,220 \\
1,830 \\
10,730\end{array}$ & $\begin{array}{l}31,310 \\
36,050 \\
57,970\end{array}$ & $\begin{array}{r}11,630 \\
-470 \\
4,750\end{array}$ \\
\hline $\begin{array}{l}l \text {-Rhamnoses. } \\
\text { Methyl } l \text {-rhamnosides } \\
\text { Phenyl } l \text {-rhamnosides. }\end{array}$ & $\begin{array}{r}7,870 \\
28,140 \\
46,490\end{array}$ & $\begin{array}{r}4,730 \\
5,860 \\
-4,450\end{array}$ & $\begin{array}{r}\quad 30,250 \\
48,540\end{array}$ & $\begin{array}{l}-1,430 \\
-10,080\end{array}$ \\
\hline
\end{tabular}

a Compiled from the data listed in table 5, p. 20.

b The differences were obtained by subtracting the molecular rotation $([\alpha] \times \mathrm{mol}$, wt. $)$ of the isomer having the smallest dextrorotation from the isomer having the largest dextrorotation. In a number of cases the temperature at which the rotations were measured was slightly greater or less than $20^{\circ} \mathrm{C}$.

- The algebraic sum of the molecular rotations of the alpha and beta isomers of the substances.

d One rotation was measured in methyl alcohol.

- Rotations measured in acetylene tetrachloride solution.

\section{RELATION BETWEEN THE VALUES OF $2 A$ OF GLUCOSIDE PAIRS AND THE MOLECULAR ROTATIONS OF THE CORRESPONDING $\beta$ - $d$-GLUCOSIDES}

In accordance with the "isorotation concept" the molecular rotation of a $\beta-d$-glucoside may be represented by the equation $M=-A+B$. Hence, if the molecular rotations of a series of glucosides are plotted against the corresponding values for $A$, the points should lie on a straight line having a slope of -1 and with the intercept on the $M$ axis having the value represented by $B$. If $2 A$ is plotted against $M$, the slope will be $1 / 2$ and the intercept again will be $B$. In the preceding section it was shown that the value of $B$ for the aliphatic glucosides is less than that of $B$ for the aromatic glucosides, and since the slopes 
are the same but the intercepts different, the two series should be represented by two parallel lines.

In figure 1 , the two lines were constructed from the values of $B$ for the aromatic and aliphatic series. These values are represented by the squares at the left of the figure. From these squares, straight lines were constructed with a slope of $-1 / 2$. The values of $2 A$ for all of the glucoside pairs which could be found in the literature were then plotted against the molecular rotations of the corresponding $\beta$ - $d$-glucosides.

All of the points except that representing the benzyl glucosides, which is represented by the triangle, fall close to the two lines which were drawn in conformity with Hudson's isorotation equation, modi-

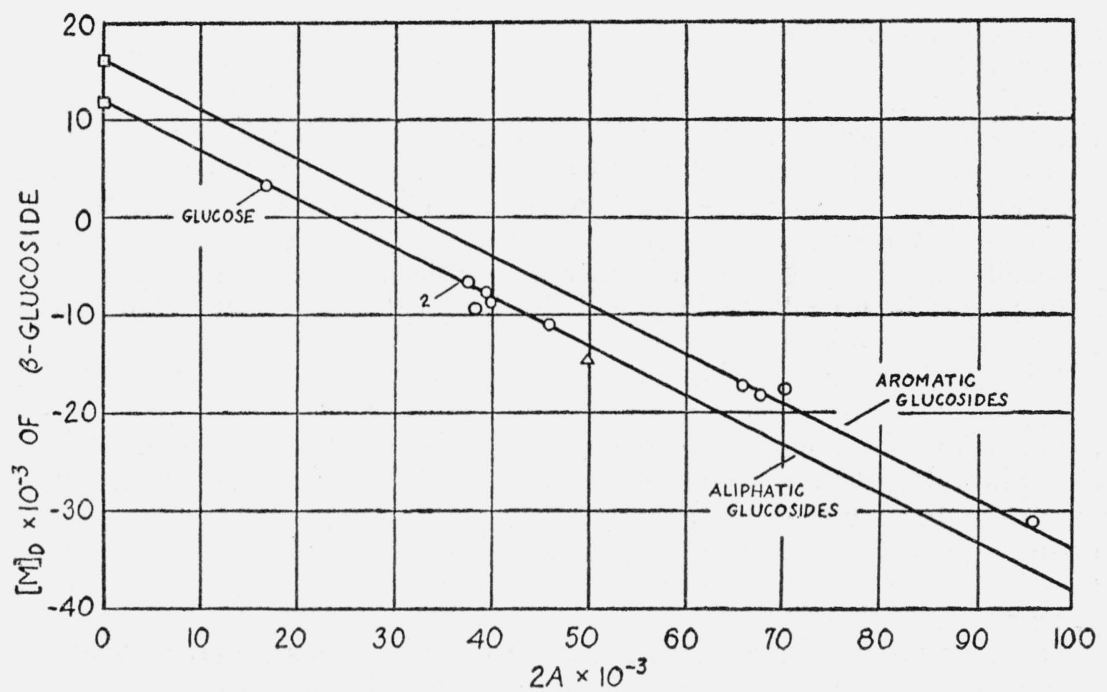

FigURE 1.-Molecular rotations of $\beta$ - $d$-glucosides and the corresponding rotatory contributions (2A) of the glucosidic carbon.

fied so that $B$ has a different value for aromatic glucosides from that for the aliphatic glucosides. Since the benzyl glucosides are of mixed aromatic and aliphatic character, a deviation is not surprising, yet the direction of the deviation is different from that which might have been expected from the mere proximity of the phenyl group.

On the basis of the regularity in the optical rotations, illustrated in figure 1 , it may be assumed that in a series of closely related $\alpha$ - or $\beta$ - $d$-glucosides the changes in optical rotation produced by a change in the aglucon group arise in large part from a change in the rotatory contribution of the first carbon of the glucoside. This generalization will be used in the next section of this paper for the purpose of explaining the effects of changes in the aglucon group on the optical rotations of the $\beta$ - $d$-glucosides. Although in the preceding discussion a sharp difference has been drawn between aromatic and aliphatic glucosides, it seems likely that when the aglucon group of aliphatic glucosides contains carbonyl groups, ethylenic linkages, conjugated systems, etc., deviations might be anticipated. Thus the allocation of the glucosides into classes having closely related aglucon groups is some- 
what arbitrary, but it justified because it permits a correlation of the optical rotation of glucosides with the electronic structure of the aglucon.

\section{RELATIONS BETWEEN THE STRUCTURE OF THE AGLUCON GROUP AND THE OPTICAL ROTATION}

In table 2 are listed the molecular rotations of the aliphatic $\beta$ - $d$ glucosides. Except for several of the lower homologues, the normal aliphatic series of glucosides appear to have about the same molecular rotations from the propyl to the $n$-hexadecyl (cetyl) glucosides (3 to 16 carbons in the aglucon). It should be noted that from the hexyl to the dodecyl glucosides the rotations are reported for methyl alcoholic solutions. The glucosides of tertiary alcohols have appreciably lower rotations than the normal and iso aliphaticg lucosides. On the other hand the introduction of hydroxy and methoxy groups into the aglucon results in only small changes in the molecular rotations. Double bonds in the $\beta-\gamma$ position and carbonyl groups in the beta position of the aglucon produce only slight increases in the rotations as is evidenced by the rotations of the allyl and glycollic acid $\beta-d$ glucosides. A glucoside with an $\alpha-\beta$ double bond would have certain similarities to an aromatic glucoside, but apparently such glucosides have not been made.

The molecular rotations of cyclohexyl $\beta-d$-glucoside and benzyl $\beta$-d-glucoside are higher than those of the aliphatic series but are lower than the molecular rotation of phenyl $\beta$-d-glucoside. When the phenyl group is situated at a greater distance from the first asymmetric carbon atom, as in the case of the phenylethyl and phenylpropyl glucosides, it loses its marked influence and the rotations of these glucosides are in the range of the rotations of the aliphatic glucosides.

As may be seen from a comparison of the values given in tables 2 and 3 , the optical rotations of aromatic $\beta$ - $d$-glucosides ordinarily are considerably more negative than those of aliphatic glucosides. The primary and secondary aliphatic $\beta$ - $d$-glucosides have molecular rotations falling in the range $-6,500$ to $-10,500$, while the rotations of the aromatic glucosides, with the exception of the diortho substituted derivatives, vary from about $-17,000$ to about $-32,000$. All of the compounds in table 3 listed above the carboxyphenyl $\beta$ - $d$-glucosides have "ortho-para directing groups" and have molecular rotations between $-17,300$ and $-20,500$. The remaining substances have "meta directing groups" substituted in the benzene nucleus. Seemingly these "meta directing groups" when in the meta or para positions enhance the molecular rotations of the glucosides, and exert their maximum effect when in the para position. The effect of the group when in the ortho position is usually small. It will be shown in a subsequent section that the effect of the substituent groups on the optical rotations parallels their effect on the dissociation constants of the corresponding phenols.

The molecular rotations of several disubstituted-phenyl glucosides for which one group is an aldehydic radical are also given in table 3. As might be expected from the meta directing effect of the CHO group, these compounds have molecular rotations larger than those of aromatic glycosides in which the $\mathrm{CHO}$ group is absent. In this 
series, however, another factor appears to influence the optical rotation, because the rotation of the compound with the CHO group in the meta position is greater than that of the compound in which the CHO group is in the para position.

TABLE 2.-Molecular rotations of aliphatic $\beta$-d-glucosides

\begin{tabular}{|c|c|c|c|}
\hline Aglucon group & $\begin{array}{c}{[M]_{D} \text { in water }} \\
t=\text { approx. } 20^{\circ} \\
\mathrm{C}\end{array}$ & {$[\alpha]_{D}$} & References \\
\hline
\end{tabular}

PRIMARY ALCOHOL SERIES

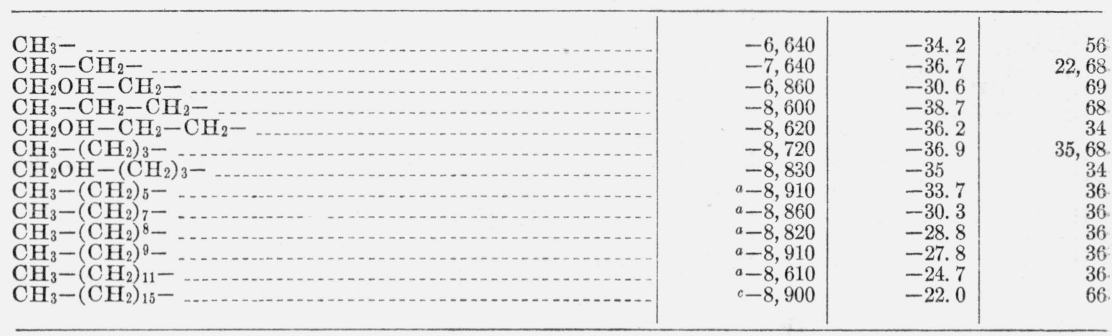

ISO SERIES

\begin{tabular}{|c|c|c|c|}
\hline $\begin{array}{l}\left(\mathrm{CH}_{3}\right)_{2} \mathrm{CH}- \\
\left(\mathrm{CH}_{3}\right)_{2} \mathrm{CH}-\mathrm{CH}_{2}- \\
\left(\mathrm{CH}_{3}\right)_{2} \mathrm{CH}-\mathrm{CH}_{2}-\mathrm{CH}{ }_{2}-\ldots\end{array}$ & $\begin{array}{l}-8,070 \\
-9,430 \\
-9,110\end{array}$ & $\begin{array}{l}-36.3 \\
-39.9 \\
-36.4\end{array}$ & $\begin{array}{r}68 \\
35,68 \\
68\end{array}$ \\
\hline
\end{tabular}

TERTIARY ALCOHOL SERIES

\begin{tabular}{ll|r|r}
\hline$\left(\mathrm{CH}_{3}\right)_{3} \mathrm{C}-{ }_{1}$ & $-4,490$ & -19.0 \\
$\left(\mathrm{CH}_{3}\right)_{2} \mathrm{C}\left(\mathrm{C}_{2} \mathrm{H}_{5}\right)-$ & $-4,480$ & 35 \\
$\mathrm{CH}_{3} \mathrm{C}\left(\mathrm{C}_{2} \mathrm{H}_{5}\right)_{2}-17.9$ & -17.0 \\
$\left(\mathrm{C}_{2} \mathrm{H}_{5}\right)_{3} \mathrm{C}-$ & $-4,490$ & 35 \\
\end{tabular}

CYCLOHEXYL AND BENZYL HOMOLOGOUS SERIES

\begin{tabular}{|c|c|c|c|}
\hline 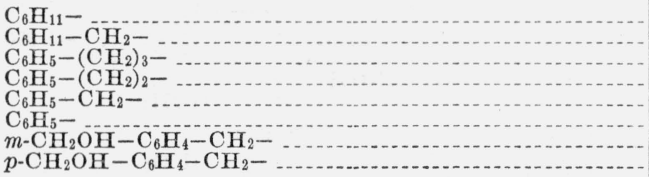 & $\begin{array}{r}-10,860 \\
-10,220 \\
-8,140 \\
-8,670 \\
-14,460 \\
-18,190 \\
-14,080 \\
-15,170\end{array}$ & $\begin{array}{l}-41.4 \\
-37.0 \\
-27.3 \\
-30.5 \\
-53.5 \\
-71 \\
-46.9 \\
-50.5\end{array}$ & $\begin{array}{r}70,23 \\
23 \\
23 \\
23 \\
66,23 \\
6,23 \\
69 \\
69\end{array}$ \\
\hline
\end{tabular}

SUBSTITUTED ALCOHOL SERIES

\begin{tabular}{|c|c|c|c|}
\hline 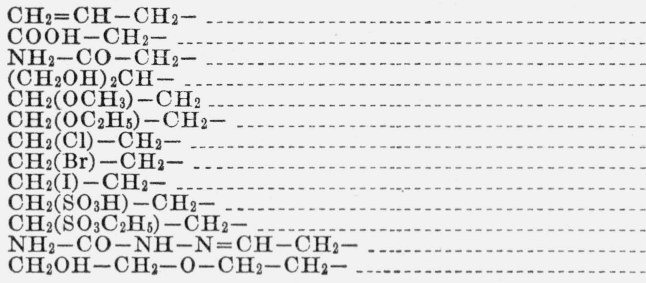 & $\begin{array}{l}-9,290 \\
-10,500 \\
-10,250 \\
-7,650 \\
-6,840 \\
-6,460 \\
-7,090 \\
-7,490 \\
-8,450 \\
-9,480 \\
-7,620 \\
-8,880 \\
-6,010\end{array}$ & $\begin{array}{l}-42.2 \\
-44.1 \\
-43.2 \\
-30.1 \\
-28.7 \\
-25.6 \\
-29.2 \\
-26.1 \\
-25.3 \\
-32.9 \\
-24.1 \\
-31.8 \\
-22.4\end{array}$ & $\begin{array}{r}68 \\
66 \\
66 \\
74 \\
34,86 \\
85 \\
57 \\
57 \\
57 \\
57 \\
57 \\
84 \\
86\end{array}$ \\
\hline
\end{tabular}

a Rotations measured in $\mathrm{CH}_{3} \mathrm{OH} ; t=25^{\circ} \mathrm{C}$.

$\checkmark$ For monohydrate. $c$ Rotation measured in $\mathrm{C}_{2} \mathrm{H}_{5} \mathrm{OH}$ at $24^{\circ} \mathrm{C}$. 
TABLE 3.-Molecular rotations of substituted-phenyl $\beta$ - $d$-glucosides

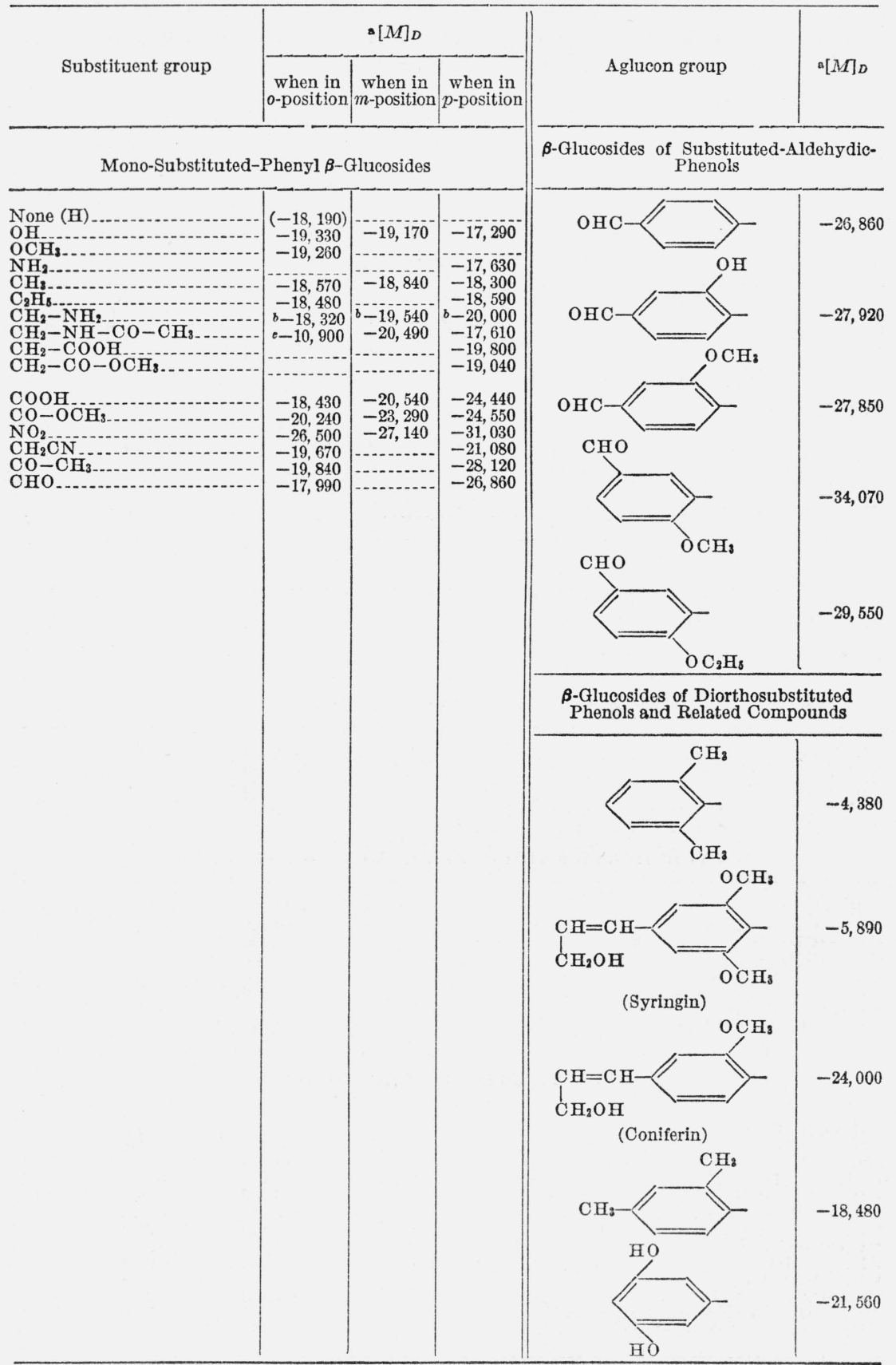

a Molecular rotations $\left([\alpha]_{D} \times\right.$ mol. wt.) for aqueous solutions at approximately $20^{\circ} \mathrm{C}$. For sources of data see table 6, p. 21 .

$b$ In aqueous acetic acid solution with acid concentration equivalent to the glucoside concentration.

- For the meta and para derivatives, the specific rotation of the acetylated derivatives are recorded as approximately $30^{\circ}$ less than those of the deacetylated derivatives, but the reverse is true for the ortho com. pounds. This suggests that one of the values may be in error. 
The molecular rotations of diorthosubstituted-phenyl glucosides, given in table 3 , show an unexpected trend. The $0,0^{\prime}$-xylenyl $\beta-d$ glucoside has a molecular rotation $(-4,380)$ which is about the same value as those characteristic of glycosides derived from tertiary alcohols. In contrast, the isomeric $o, p$-xylenyl $\beta$-d-glucoside has a value $(-18,480)$ which does not differ widely from what might be expected from the rotations of the monosubstituted phenyl glycosides containing an $\mathrm{OH}$ group in either the ortho or the para position. Although the optical rotation of the $0, o^{\prime}$-xylenyl $\beta$ - $d$-glucoside seems unusual, it is probably correct because the analogous compound, syringin, which has two methoxy groups in the ortho positions, has a molecular rotation of $-5,890$ while coniferin, in which only one of the ortho positions is substituted, has a molecular rotation of $-24,000$. The study of other diorthosubstituted derivatives is necessary to show whether or not this property is characteristic of all diorthosubstituted-phenyl glucosides.

It is interesting to note the resemblance in rotation of the tertiary aliphatic $\beta$-glucosides and the diorthosubstituted $\beta$-glucosides. Could this be due to the lack of a hydrogen atom on the carbons near the asymmetric center principally affected? The tertiary aliphatic glucosides and the phenyl glucosides have no hydrogen on the carbon forming the glucosidic linkage. The phenyl glucosides however, have hydrogens in the ortho as well as the meta positions, which because of the coujugated system present would be expected to act as a hydrogen on the carbon forming the glucosidic linkage. For the monoorthosubstituted-phenyl glucosides one hydrogen atom is replaced and for the disubstituted-phenyl glucosides both hydrogen atoms are replaced by other groups. In respect to hydrogen atoms near the carbon forming the glucosidic linkage, there is then some resemblance between the tertiary aliphatic glucosides and the diorthosubstituted-phenyl glucosides.

\section{CORRELATION OF THE OPTICAL ROTATION OF ARO- MATIC GLYCOSIDES WITH THE DISSOCIATION CON- STANTS OF THE CORRESPONDING PHENOLS}

In 1930 Betti [7] pointed out a correlation between the optical rotation of substances of the general formula

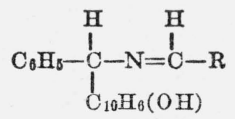

(where $\mathrm{R}$ is a substituted benzene ring) and the dissociation constants of the corresponding acids of the general formula $\mathrm{RCOOH}$. In order to test the possibility that a similar relation might hold for the optical rotations of the substituted phenyl glucosides and the dissociation constants of the corresponding phenols, the optical rotation of phenyl $\beta$-d-glucoside and of 10 substituted-phenyl $\beta$ - $d$-glucosides were plotted (see fig. 2 and table 4 ) against the $p K$ values of the corresponding phenols recently reported by Schwarzenbach and Rudin [8]. As illustrated by figure 2, the points fall fairly close to a straight line. Although the deviations from linearity appear to be greater than the errors of the measurements, it seems that there is an approximate 
relationship between the optical rotation and the $p K$ values. This correlation is based on 10 points, including six parasubstituted phenols, two metasubstituted phenols, and one orthosubstituted phenol. An additional point representing the 0 -nitrophenyl glucoside does not agree with the above correlation but an explanation for this may be found in the well-known tendency of certain orthosubstituted phenols to form chelate rings by hydrogen bonding, a process which does not seem possible for the corresponding phenyl glucosides.

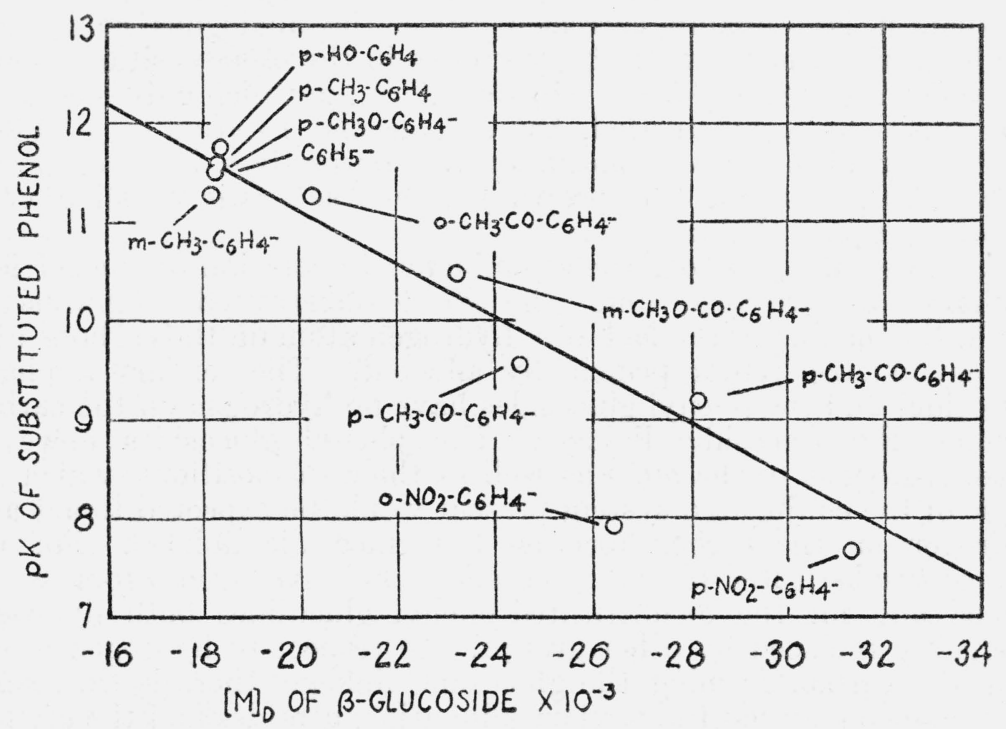

FIGURE 2.-Relationship between the $p K$ values of phenols and the molecular rotations of the corresponding $\beta$-glucosides.

TABLE 4.-Acid strengths of phenols and molecular rotation of corresponding $\beta$ - $d$-glucosides

\begin{tabular}{|c|c|c|c|c|c|}
\hline $\begin{array}{l}\text { Group substituted in the } \\
\text { phenol and phenyl glucoside }\end{array}$ & $p K^{a}$ & $\mathrm{~b}[M]_{D}^{20}$ & $\begin{array}{l}\text { Group substituted in the } \\
\text { phenol and phenyl glucoside }\end{array}$ & $p K^{\mathrm{a}}$ & $\mathrm{b}[M]_{D}^{20}$ \\
\hline $\begin{array}{l}\text { None- } \\
p-\mathrm{OH}- \\
p-\mathrm{CH}_{3} \\
p-\mathrm{OCH}_{3} \\
m-\mathrm{CH}_{3}-\mathrm{CH}_{3} \\
o-\mathrm{CO}-\mathrm{O} \mathrm{CH}_{3-2}\end{array}$ & $\begin{array}{l}\text { 11. } 28 \\
\text { 11. } 78 \\
11.61 \\
11.52 \\
11.43 \\
11.28\end{array}$ & $\begin{array}{l}-18,190 \\
-18,390 \\
-18,300 \\
-18,240 \\
-18,840 \\
-20,240\end{array}$ & $\begin{array}{l}m-\mathrm{CO}-\mathrm{OCH}_{3}- \\
p-\mathrm{CO}-\mathrm{OCH}_{3}-\mathrm{CH}_{3} \\
p-\mathrm{CO}-\mathrm{CH}_{3} \\
p-\mathrm{NO}_{2} \\
0-\mathrm{NO}_{2}\end{array}$ & $\begin{array}{r}10.50 \\
9.58 \\
9.21 \\
7.68 \\
7.93\end{array}$ & $\begin{array}{l}-23,290 \\
-24,550 \\
-28,120 \\
-31,030 \\
-26,500\end{array}$ \\
\hline
\end{tabular}

a Data of Schwarzenbach and Rudin [8] for solutions of phenols in alcohol-water mixtures (48 percent of ethyl alcohol) at 20 to $22^{\circ} \mathrm{C}$.

b Molecular rotation in water. For source of data, see references in table 6 .

The linear relationship indicated by figure 2 appears to be in harmony with the observations of Rule [9] and with the calculations of Kauzmann, Walter, and Eyring [10, p. 394]. The compounds used by Betti have the advantage over the glucosides in that they contain only one asymmetric atom, but this advantage is largely off'set by the application of Hudson's isorotation principle, which gives at least an approximate value for the optical rotation of the asymmetric center 
principally affected. This was shown by the data presented in figure 1 , which revealed that the molecular rotation of the aromatic $\beta$-glucosides varies approximately directly with the rotatory contribution of the first carbon. The relationship between the optical rotations of the $\beta$-glucosides and the dissociation constants is then essentially one between the rotatory contribution of the first carbon and the strength of the bond connecting the first carbon atom and the oxygen atom of the glucosidic linkage. The following formulas illustrate this relation:
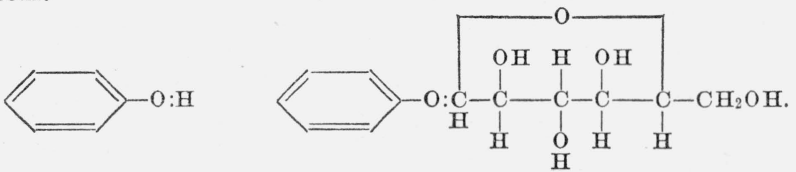

For phenols the dissociation constants (also the $p K$ values), for constant external conditions, are functions of the strengths of the bonds between the oxygen atoms and the ionizable hydrogen atoms. In the phenyl glucosides this bond, as represented above, is the bond connecting the oxygen atom to the asymmetric carbon atom. Thus, the pair of electrons forming this bond appears to play an important part in determining the magnitude of the optical rotation.

The relationship between the rotatory power of the aromatic $\beta$ glucosides and the dissociation constants of the phenols may be of value for estimating approximate $p K$ values for the phenols. As mentioned previously, however, orthosubstituted phenols and their glucosides may provide an exceptional class because of the proximity of the group in the ortho position to the phenolic oxygen. This may be particularly evident when the group in the ortho position readily forms chelate rings. Inasmuch as the dissociation constants of the phenols are considerably larger than the dissociation constants of the alcohols and of water, the smaller levorotations of the aliphatic $\beta-d$-glucosides and of $\beta$ - $d$-glucose appear to be in qualitative accord with a correlation of the optical rotation with the dissociation constants. 


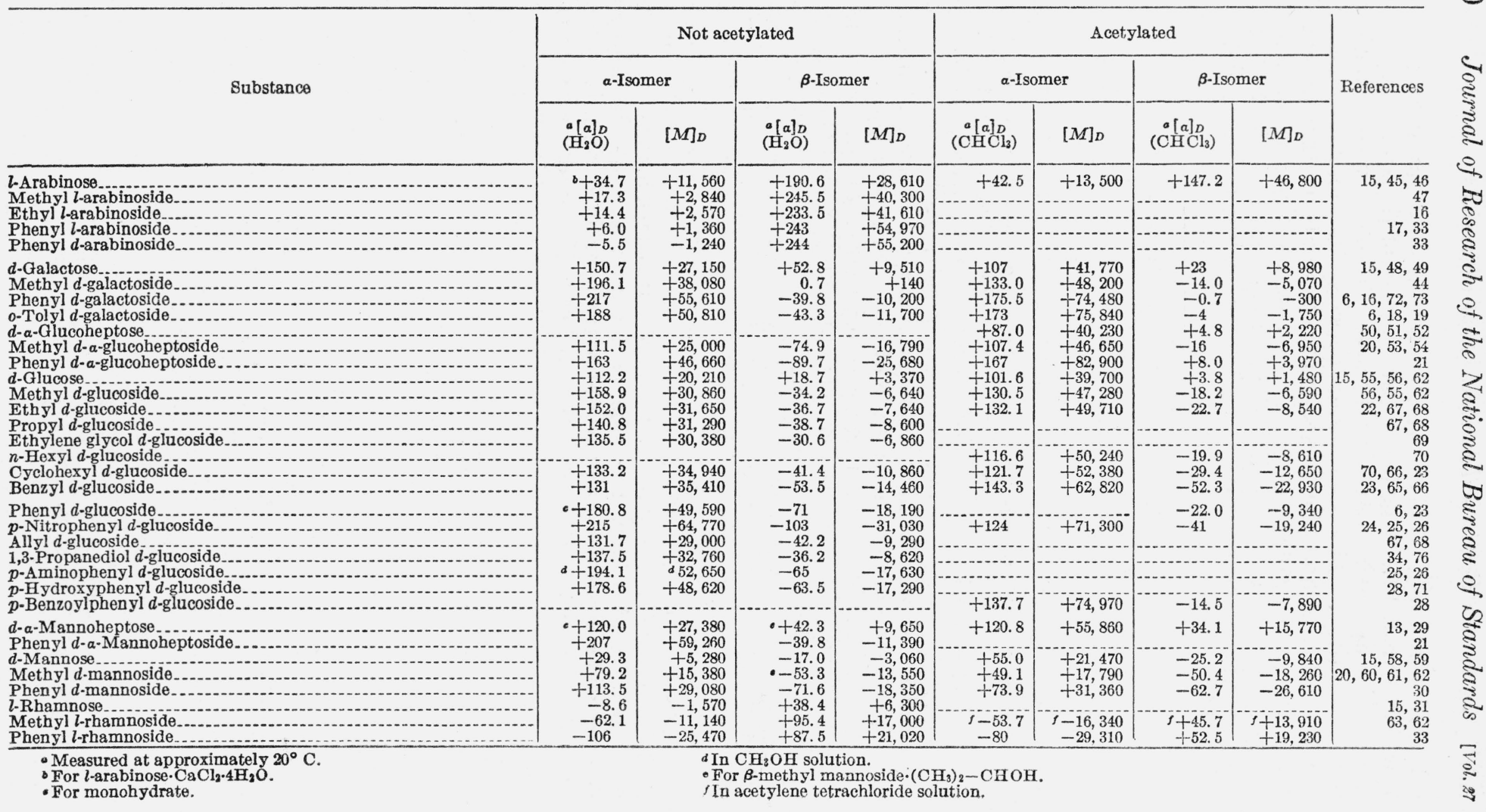


TABLE 6.-Specific rotation of substituted-phenyl $\beta$-d-glucosides

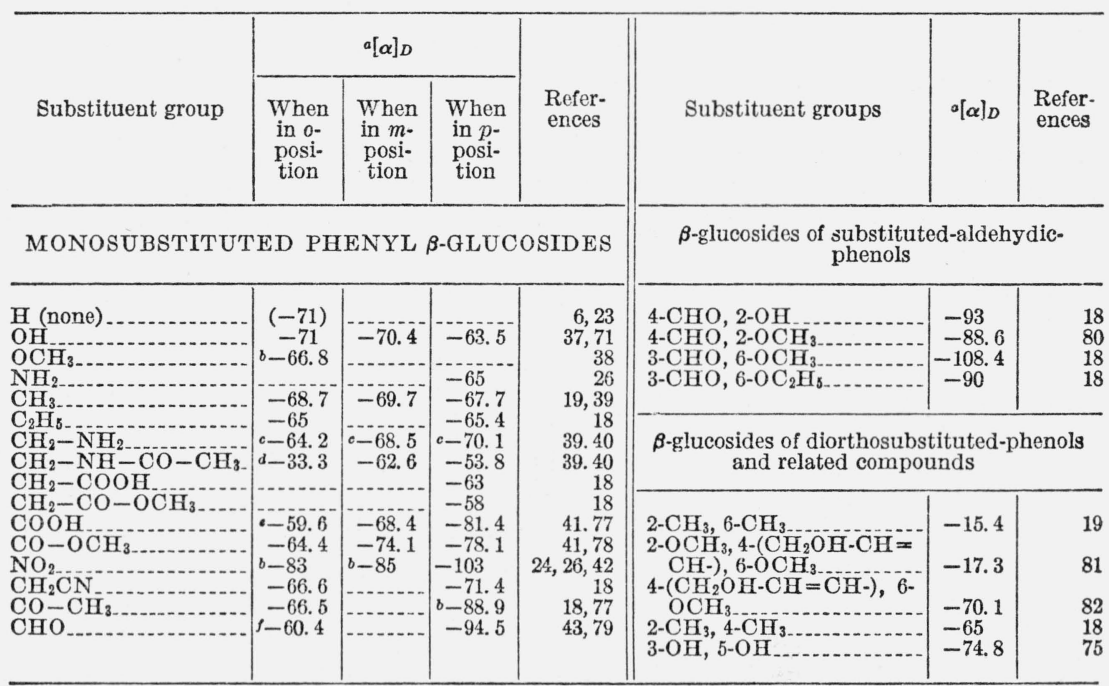

a In water at approximately $20^{\circ} \mathrm{C}$.

$\checkmark$ For the monohydrate.

- For aqueous solutions containing acetic acid equivalent to the glucoside concentration.

d See table 3 , footnote c.

- For glucoside $1 / 2 \mathrm{H}_{2} \mathrm{O}$.

$f$ For glucoside $3 / 4 \mathrm{H}_{2} \mathrm{O}$.

\section{EXPERIMENTAL DETAILS}

\section{GENERAL PROCEDURE}

The new phenyl glycosides were prepared by the method of Helferich and Schmitz-Hillebrecht [6]. The method consists in heating an acetylated sugar with phenol and a catalyst (anhydrous zinc chloride or $p$-toluenesulphonic acid). After the mixture has cooled, it is extracted with benzene and water and the benzene extracts are washed with $2 N$ sodium hydroxide to remove the excess phenol. The benzene extracts upon evaporation give the acetylated glycoside, which upon solution in absolute methanol and treatment with very small amounts of barium methylate at the boiling point for 10 minutes $[11,12]$ is converted to the phenyl glycoside.

For each of the following compounds, the time of heating and the catalyst used are given.

\section{PHENYL $d$ - $\alpha$-MANNOHEPTOSIDES}

\section{Preparation of Hexaacetyl- $\beta-d-\alpha-$ mannoheptose.}

The preparation of this compound was previously reported by Montgomery and Hudson [13], but as considerably better yields have been obtained, the method used is described.

To a mixture of $50 \mathrm{ml}$ of acetic anhydride and $70 \mathrm{ml}$ of pyridine at room temperature there was added in small portions $10 \mathrm{~g}$ of $d$ - $\alpha$ mannoheptose. The solution was kept at room temperature for 48 hours and then poured into ice water. Crystallization occurred, the crystals were separated by filtration, and the filtrate was extracted with chloroform. A total of $18.5 \mathrm{~g}$ of crude hexacetyl- $\beta-\alpha-\alpha$-manno- 
heptose was obtained ( $17 \mathrm{~g}$ by direct crystallization and $1.5 \mathrm{~g}$ from the chloroform extract). This corresponds to a yield of 80 percent of the theory as compared to one of 58 percent reported by Montgomery and Hudson [13] by the sodium acetate method.

Phenyl d- $\alpha$-mannoheptosides.

Under the condition employed, both catalysts (zinc chloride and $p$-toluenesulphonic acid) gave mixtures of the $\alpha$ - and $\beta$-glycosides and the acetylated glycosides were not obtained in the crystalline condition.

A mixture of $3 \mathrm{~g}$ of hexaacetyl- $\beta-d-\alpha$-mannoheptose, $3 \mathrm{~g}$ of phenol, and $0.2 \mathrm{~g}$ of $p$-toluenesulphonic acid was heated on the boiling water bath for 1 hour, and the mixture was treated as described under the "general procedure" (p. 21). A sirup was obtained which upon deacetylation gave the crystalline phenyl $d$ - $\alpha$-mannoheptosides. The first material obtained from methyl alcohol was fairly pure alpha isomer, while the mother liquors gave mixtures of the two isomers. About $0.3 \mathrm{~g}$ of the alpha and $0.3 \mathrm{~g}$ of the mixture of isomers were obtained. These were purified as described below.

The heating of a mixture of $3 \mathrm{~g}$ of the hexaacetyl- $\beta-d$ - $\alpha$-mannoheptose, $3 \mathrm{~g}$ of phenol, and $1 \mathrm{~g}$ of anhydrous zine chloride for 1 hour on the boiling water bath gave practically the same proportions and amounts of the two isomers as when the previous procedure was used.

The impure alpha isomer (mp $195^{\circ}$ to $205^{\circ} \mathrm{C}$ ) obtained from dilute methyl alcohol solutions of the deacetylated mixture is readily purified by recrystallization from methyl alcohol. The pure material melts at $212^{\circ} \mathrm{C}$ (corr.), and the rotation in water is $[\alpha]_{D}^{20}=+207(c, 0.8 ; 0.0789 \mathrm{~g}$ made up to a volume of $10 \mathrm{ml}$ read $9.45^{\circ} \mathrm{S}$ in a 2 -dm tube). The alpha isomer is the less soluble of the two isomers in water and in methyl alcohol, and a saturated aqueous solution at $20^{\circ} \mathrm{C}$ contains about $0.8 \mathrm{~g}$ in $100 \mathrm{ml}$. Analysis: Calculated for $\mathrm{C}_{13} \mathrm{H}_{18} \mathrm{O}_{7}$ : C, 54.54; $\mathrm{H}, 6.34$; Found: $\mathrm{C}, 54.8 ; \mathrm{H}, 6.3$.

Considerable difficulty was experienced in the preparation of the pure beta isomer, but the following procedure was found to be satisfactory. One gram of a mixture was dissolved in $6 \mathrm{ml}$ of hot water, and the solution was cooled. The crystals which separated were fairly pure alpha isomer. The solution remaining was evaporated to dryness and the residue recrystallized from $25 \mathrm{ml}$ of hot absolute alcohol. The material so obtained had a rotation of $[\alpha]_{D}^{20}=-23$. This mixture after two recrystallizations from absolute alcohol gave pure phenyl $\beta-d-\alpha$-mannoheptoside with melting point of 189 to $190^{\circ} \mathrm{C}$ (corr.) and $[\alpha]_{D}^{20}=-39.8$ (water; $c, 1.1 ; 0.1100 \mathrm{~g}$ made up to a volume of $10 \mathrm{ml}$ read $-2.53^{\circ} \mathrm{S}$ in a 2-dm tube). Analysis: Calculated for $\mathrm{C}_{13} \mathrm{H}_{18} \mathrm{O}_{7}$ : C, $54.54 ; \mathrm{H}, 6.34$; Found: C, $54.2 ; \mathrm{H}, 6.0$.

\section{PHENYL d-TALOSIDES}

A mixture of $2.5 \mathrm{~g}$ of pentaacetyl- $\alpha$ - $d$-talose, $2.5 \mathrm{~g}$ of phenol, and $0.5 \mathrm{~g}$ of anhydrous zinc chloride was heated on the water bath for 2 hours. The product was carried through the general procedure described above and gave a sirup which crystallized from ethyl alcohol. Yield: $1.0 \mathrm{~g}$ of phenyl tetraacetyl- $\alpha-d$-taloside. This was purified by several recrystallizations from methyl or ethyl alcohol. The purified material melted at 103.5 to $104.0^{\circ} \mathrm{C}$ (corr.). The rotation was $[\alpha]{ }_{D}^{20}=+97.4\left(\mathrm{CHCl}_{3} ; c, 3.5 ; 0.1052 \mathrm{~g}\right.$ made up to a volume of 3.024 
$\mathrm{ml}$ read $+9.79^{\circ} \mathrm{S}$ in a 1 -dm tube). Analysis: Calculated for $\mathrm{C}_{20} \mathrm{H}_{24} \mathrm{O}_{10}$ : C, $56.60 ; \mathrm{H}, 5.70$; Found: C, 56.7 ; H, 5.5.

The phenyl $\alpha$-d-taloside was obtained by deactylating the tetraacetate, and after several recrystallizations from alcohol and finally from water it had a melting point of 165.5 to $166.5^{\circ} \mathrm{C}$ (corr.) and a rotation of $[\alpha]_{D}^{20}=+138\left(\mathrm{H}_{2} \mathrm{O} ; c, 0.9 ; 0.0894 \mathrm{~g}\right.$ made up to a volume of $10 \mathrm{ml}$, read $7.11^{\circ} \mathrm{S}$ in a $2-\mathrm{dm}$ tube). The solubility of the compound in water at $20^{\circ}$ is $0.5 \mathrm{~g}$ in $100 \mathrm{ml}$. Analysis: Calculated for $\mathrm{C}_{12} \mathrm{H}_{16} \mathrm{O}_{6}$ : C, 56.24 ; H, 6.29 ; Found: C, $56.3 ; \mathrm{H}, 6.2$.

\section{PHENYL $d$ - $\alpha$-GLUCOHEPTOSIDES}

A mixture of $6.7 \mathrm{~g}$ of hexaacetyl- $\beta-d-\alpha$-glucoheptose, $7 \mathrm{~g}$ of phenol, and $2 \mathrm{~g}$ of anhydrous zinc chloride was heated for 2 hours in a boiling water bath. The product was treated as previously described and the sirup, when dissolved in ethyl alcohol, crystallized. The first impure crystals, consisting principally of the alpha isomer, which appear under the microscope as square or rectangular plates, melted at $140^{\circ} \mathrm{C}$ and weighed $2.1 \mathrm{~g}$. The mother liquors yielded about $1 \mathrm{~g}$ more of a mixture of the alpha and beta forms (melting point approximately $100^{\circ} \mathrm{C}$ ). Total yield: $3.1 \mathrm{~g}$.

The higher-melting material upon recrystallization from methyl alcohol readily gave the pure phenyl pentaacetyl- $d-\alpha$-glucoheptoside, which melts at 154.0 to $155.0^{\circ} \mathrm{C}$ (corr.) and gives $[\alpha]_{D}^{2 \mathrm{C}}=+167$ $\left(\mathrm{CHCl}_{3} ; c, 3.0 ; 0.3022 \mathrm{~g}\right.$ made up to a volume of $10 \mathrm{ml}$ read $29.15^{\circ} \mathrm{S}$ in a 2 -dm tube). Analysis: Calculated for $\mathrm{C}_{23} \mathrm{H}_{28} \mathrm{O}_{12}: \mathrm{C}, 55.64 ; \mathrm{H}$, 5.68; Found: C, 55.8; H, 5.8.

The beta isomer, which crystallizes from alcohol in pointed prisms, was more difficult to purify. However, purification was accomplished by crystallization from carbon tetrachloride as described by Fischer for the phenyl galactosides. The relative solubilities of the alpha and beta isomers of the acetylated phenyl glycosides are apparently completely different in carbon tetrachloride from those in solvents such as the alcohols. In $2 \mathrm{ml}$ of warm carbon tetrachloride, there was dissolved $0.4 \mathrm{~g}$ of a mixture of the two isomers $\left([\alpha]_{D}^{20}=+38\right)$. After the solution had stood for some time at $+5^{\circ} \mathrm{C}$, the crystals were separated (wt $0.12 \mathrm{~g}$ ) and found to have the rotation: $[\alpha]_{\mathrm{D}}^{20}=+9.9$. The phenyl pentaacetyl- $\beta-d$-a-glucoheptoside obtained by recrystallizing the above material several times from absolute ethyl alcohol melted at $97^{\circ} \mathrm{C}$ (corr.). The rotation was $[\alpha]_{D}^{20}=+8.0\left(\mathrm{CHCl}_{3} ; c, 1.1\right.$; $0.1107 \mathrm{~g}$ made up to a volume of $10 \mathrm{ml}$ read $+0.51^{\circ} \mathrm{S}$ in a $2-\mathrm{dm}$ tube). Analysis: Calculated for $\mathrm{C}_{23} \mathrm{H}_{28} \mathrm{O}_{12}$ : C, 55.64; H, 5.69; Found: C, $55.8 ; \mathrm{H}, 5.6$.

The phenyl $\alpha$ - $d$ - $\alpha$-glucoheptoside, obtained by deacetylation of the pentaacetate, after recrystallization from methyl alcohol melted at 191 to $192^{\circ} \mathrm{C}$ (corr.) and had as the specific rotation $[\alpha]_{D}^{20}=+163$ $\left(\mathrm{H}_{2} \mathrm{O} ; c, 1.0 ; 0.1015 \mathrm{~g}\right.$ made up to a volume of $10 \mathrm{ml} \mathrm{read}+9.74^{\circ} \mathrm{S}$ in a 2-dm tube). Analysis: Calculated for $\mathrm{C}_{13} \mathrm{H}_{18} \mathrm{O}_{7}$ : C, 54.54; H, 6.34; Found: C, $54.8 ; \mathrm{H}, 6.3$.

The phenyl $\beta$ - $d$ - $\alpha$-glucoheptoside, obtained in a similar manner, after one recrystallization from isopropyl alcohol melted at 167 to $168^{\circ} \mathrm{C}$ (corr.). The specific rotation was measured as $[\alpha]_{D}^{20}=-89.7$ $\left(\mathrm{H}_{2} \mathrm{O} ; c, 0.9 ; 0.0272 \mathrm{~g}\right.$ made up to a volume of $3.024 \mathrm{ml}$ read $2.33^{\circ} \mathrm{S}$ in a 1-dm tube). Analysis: Calculated for $\mathrm{C}_{13} \mathrm{H}_{18} \mathrm{O}_{7}$ : C, 54.54; H, 6.34; Found: C,54.4; H, 6.3. 


\section{REFERENCES}

Many of the rotational values used in the present paper are assembled in the several handbooks available (see [4] and [14]. Reference [1] and Circular C429 of the National Bureau of Standards, Polarimetry, Saccharimetry and the Sugars (publication pending) have also very useful compilations of optical rotational values for the sugars and derivatives. The references given in the present paper are to the actual data used and not necessarily to original work which, however, can be located from the above-mentioned compilations.

[1] C. S. Hudson, BS Sci. Pap. 21, 241 (1926) S533.

[2] C. S. Hudson, Rapports sur les Hydrates de Carbone, p. 59 (10th Conference of the International Union of Chemistry, Liege, 1930).

[3] E. E. and K. F. Armstrong, The Carbohydrates, p. 41. (Longmans, Green and Co., London, 1934).

[4] Tollens-Elsner, Kurzes Handbuch der Kohlenhydrate, 5th ed., p. 84. (Johann Barth, Leipzig, 1935).

[5] T. M. Lowry, Optical Rotatory Power, p. 408. (Longmans, Green and Co., London, 1935).

[6] B. Helferich and E. Schmitz-Hillebrecht, Ber. deut. chem. Ges. 66, 378 (1933).

[7] M. Betti, Trans. Faraday Soc. 26, 337 (1930).

[8] G. Schwarzenbach and E. Rudin, Helv. Chim. Acta 22, 360 (1939).

[9] H. G. Rule, Trans. Faraday Soc. 26, 321 (1930).

[10] W. Kauzmann, J. Walter, and H. Eyring, Chem. Reviews 26, 339 (1940).

[11] H. S. Isbell, BS J. Research 5, 1185 (1930) RP253.

[12] G. Zemplen and E. Pacsu, Ber. deut. chem. Ges. 62, 1613 (1927).

[13] E. Montgomery and C. S. Hudson, J. Am. Chem. Soc. 56, 2463 (1934).

[14] H. Vogel and A. Georg, Tabellen der Zucker und Ihrer Derivate (Julius Springer, Berlin, 1931).

[15] H. S. Isbell and W. W. Pigman, J. Research NBS 18, 141 (1937) RP969.

[16] B. Helferich and H. Appel, Z. physiol. Chem. 205, 231 (1932).

[17] B. Helferich, S. Winkler, R. Gootz, O. Peters, and E. Günther, Z. physiol. Chem. 208, 91 (1932).

[18] B. Helferich, H. Scheiber, R. Streeck, and F. Vorsatz, Liebigs Ann. Chem. 518, 211 (1935).

[19] B. Helferich and H. Scheiber, Z. physiol. Chem. 226, 272 (1934).

[20] H. S. Isbell and H. L. Frush, J. Research NBS 24, 125 (1940).

[21] See experimental part of this paper, page 21 .

[22] J. Ferguson, J. Am. Chem. Soc. 54, 4086 (1932).

[23] N. K. Richtmyer, J. Am. Chem. Soc. 56, 1633 (1934).

[24] K. Aizawa, J. Biochem. (Japan) 30, 89 (1939).

[25] W. F. Goebel, F. Babers, and O. T. Avery, J. Exp. Med. 55, 761 (1932); W. Goebel and O. Avery, J. Exp. Med. 50, 521 (1929).

[26] B. Helferich and O. Peters, J. prakt. Chem. 138, 281 (1933).

[27] I. Wolfe, Diss. Hamburg (1929).

[28] B. Helferich and W. Reischel, Liebigs Ann. Chem. 533, 278 (1938).

[29] H. S. Isbell, J. Research NBS 18, 505 (1937) RP990.

[30] B. Helferich and S. Winkler, Ber. deut. chem. Ges. 66, 1556 (1933).

[31] E. L. Jackson and C. S. Hudson, J. Am. Chem. Soc. 59, 1076 (1937).

[32] J. Minsaas, Kgl. Norske Videnskab. Selskabs Forh. 6, 177 (1934).

[33] B. Helferich, H. Appel, and R. Gootz, Z. physiol. Chem. 215, 277 (1933).

[34] B. Helferich and R. Hiltmann, Liebigs Ann. Chem. 531, 160 (1937).

[35] S. Veibel and H. Lillelund, Bul. soc. chim. [5] 5, 494 (1938).

[36] C. R. Noller and W. C. Rockwell, J. Am. Chem. Soc. 60, 2076 (1938).

[37] B. Helferich, O. Lang, and E. Schmitz-Hillebrecht, J. prakt. Chem. 138, 276 (1933).

[38] B. Helferich and P. Burt, Liebigs Ann. Chem. 520, 156 (1935).

[39] B. Helferich and F. Philipp, Liebigs Ann. Chem. 514, 228 (1934).

[40] B. Helferich, E. Günther, and S. Winkler, Liebigs Ann. Chem. 508, 192 (1933).

[41] B. Helferich and H. Lutzmann, Liebigs Ann. Chem. 53\%, 11 (1938).

[42] E. Glaser and W. Wulwek, Biochem. Z. 145, 521 (1924).

[43] F. Mauthner, J. prakt. Chem. 85, 564 (1912).

[44] J. K. Dale and C. S. Hudson, J. Am. Chem. Soc. 52, 2534 (1930). 
[45] W. C. Austin and J. Walsh, J. Am. Chem. Soc. 56, 934 (1934); E. Montgomery and C. S. Hudson, J. Am. Chem. Soc. 56, 2074 (1934).

[46] C. S. Hudson and J. K. Dale, J. Am. Chem. Soc. 40, 995 (1918).

[47] C. S. Hudson, J. Am. Chem. Soc. 47, 265 (1925).

[48] C. S. Hudson and J. M. Johnson, J. Am. Chem. Soc. 38, 1224 (1916).

[49] C. S. Hudson and H. O. Parker, J. Am. Chem. Soc. 3\%, 1589 (1915).

[50] E. Glaser and N. Zuckermann, Z. physiol. Chem. 166, 103; 16\%, 37 (1927).

[51] C. S. Hudson and E. Yanovsky, J. Am. Chem. Soc. 38, 1575 (1916).

[52] E. Fischer, Liebigs Ann. Chem. 270, 64 (1892).

[53] W. N. Haworth, E. L. Hirst, and M. Stacey, J. Chem. Soc. 1931, 2864.

[54] E. Fischer, Ber. deut. chem. Ges. 28, 1156 (1895).

[55] C. S. Hudson and J. K. Dale, J. Am. Chem. Soc. 37, 1264 (1915).

[56] C. N. Riiber, Ber. deut. chem. Ges. 5\%, 1797 (1924).

[57] B. Helferich and H. Lutzmann, Liebigs Ann. Chem. 541, 1 (1939).

[58] C. S. Hudson and J. K. Dale, J. Am. Chem. Soc. 37, 1280 (1915).

[59] E. Fischer and R. Oetker, Ber. deut. chem. Ges. 46, 4029 (1913).

[60] E. Fischer and L. Beensch, Ber. deut. chem. Ges. 29, 2927 (1896).

[61] H. Hérissey, Compt. rend. 173, 1406 (1921).

[62] T. L. Harris, E. L. Hirst, and C. E. Wood, J. Chem. Soc. 1932, 2108.

[63] E. Fischer, M. Bergmann, and A. Rabe, Ber. deut. chem. Ges. 53, 2362 (1920).

[64] M. Gomberg and C. Buchler, J. Am. Chem. Soc. 43, 1904 (1922).

[65] B. Helferich and R. Gootz, Ber. deut. chem. Ges. 62, 2788 (1929).

[66] E. Fischer and B. Helferich, Liebigs Ann. Chem. 383, 68 (1911).

[67] E. Bourquelot, Ann. chim. [9] 3, 287 (1915).

[68] E. Bourquelot and M. Bridel, Ann. chim. phys. [8] 29, 145 (1913).

[69] E. Bourquelot, Ann. chim. [9] 4, 310 (1915).

[70] E. Pacsu, J. Am. Chem. Soc. 52, 2563 (1930); 52, 2568 (1930).

[71] H. Hérissey, Compt. rend. 151, 444 (1910).

[72] B. Helferich and $H$. Brederick, Liebigs Ann. Chem. 465, 166 (1928).

[73] E. Fischer and E. F. Armstrong, Ber. deut. chem. Ges. 35, 833 (1902).

[74] N. Carter, Ber. deut. chem. Ges. 63, 1684 (1930).

[75] E. Fischer and H. Strauss, Ber. deut. chem. Ges. 45, 2467 (1912).

[76] I. Vintilesco, C. N. Ionesco, and A. Kizyk, Bul. Chim. Soc. Române Chim. 1\%, 131 (1935).

[77] F. Mauthner, J. prakt. Chem. 88, 764 (1913).

[78] T. Sabalitachka and F. L. Schweitzer, Arch. Pharm. 267, 675 (1929).

[79] F. Tiemann, Ber. deut. chem. Ges. 18, 1595 (1885).

[80] E. Fischer and K. Raske, Ber. deut. chem. Ges. 42, 1465 (1909).

[81] H. Pauly and L. Strassberger, Ber. deut. chem. Ges. 62, 2277 (1929).

[82] G. Zemplén, Z. physiol. Chem. 85, 414 (1913).

[83] E. Fischer and L. v. Mechel, Ber. deut. chem. Ges. 49, 2813 (1916).

[84] B. Helferich and J. Goerdeler, Ber. deut. chem. Ges. 73, 532 (1940).

[85] I. Vintilesco, C. N. Ionesco, and A. Kizyk, Bul. Chim. Soc. Române Chim. 16, $151(1934)$.

[86] S. Karjala and K. P. Link, J. Am. Chem. Soc. 62, 917 (1940).

Washington, May 9, 1941. 